\title{
Standardization procedures for real-time breath analysis by secondary electrospray ionization high-resolution mass spectrometry
}

\author{
Kapil Dev Singh ${ }^{1,2} \cdot$ Georgi Tancev $^{1,2} \cdot$ Fabienne Decrue $^{1} \cdot$ Jakob Usemann $^{1} \cdot$ Rhea Appenzeller $^{1} \cdot$ Pedro Barreiro $^{3}$. \\ Gabriel Jaumà $^{3}$. Miriam Macia Santiago ${ }^{3}$. Guillermo Vidal de Miguel $^{3} \cdot$ Urs Frey $^{1,2} \cdot$ Pablo Sinues $^{1,2}$ (I)
}

Received: 3 December 2018 / Revised: 25 February 2019 / Accepted: 6 March 2019 / Published online: 15 April 2019

(C) The Author(s) 2019

\begin{abstract}
Despite the attractiveness of breath analysis as a non-invasive means to retrieve relevant metabolic information, its introduction into routine clinical practice remains a challenge. Among all the different analytical techniques available to interrogate exhaled breath, secondary electrospray ionization high-resolution mass spectrometry (SESI-HRMS) offers a number of advantages (e.g., real-time, yet wide, metabolome coverage) that makes it ideal for untargeted and targeted studies. However, so far, SESI-HRMS has relied mostly on lab-built prototypes, making it difficult to standardize breath sampling and subsequent analysis, hence preventing further developments such as multi-center clinical studies. To address this issue, we present here a number of new developments. In particular, we have characterized a new SESI interface featuring real-time readout of critical exhalation parameters such as $\mathrm{CO}_{2}$, exhalation flow rate, and exhaled volume. Four healthy subjects provided breath specimens over a period of 1 month to characterize the stability of the SESI-HRMS system. A first assessment of the repeatability of the system using a gas standard revealed a coefficient of variation (CV) of $2.9 \%$. Three classes of aldehydes, namely 4-hydroxy-2-alkenals, 2-alkenals and 4-hydroxy-2,6-alkedienals-hypothesized to be markers of oxidative stress-were chosen as representative metabolites of interest to evaluate the repeatability and reproducibility of this breath analysis analytical platform. Median and interquartile ranges (IQRs) of CVs for $\mathrm{CO}_{2}$, exhalation flow rate, and exhaled volume were $3.2 \%(1.5 \%), 3.1 \%$ (1.9\%), and 5.0\% (4.6\%), respectively. Despite the high repeatability observed for these parameters, we observed a systematic decay in the signal during repeated measurements for the shorter fatty aldehydes, which eventually reached a steady state after three/four repeated exhalations. In contrast, longer fatty aldehydes showed a steady behavior, independent of the number of repeated exhalation maneuvers. We hypothesize that this highly molecule-specific and individual-independent behavior may be explained by the fact that shorter aldehydes (with higher estimated blood-to-air partition coefficients; approaching 100) mainly get exchanged in the airways of the respiratory system, whereas the longer aldehydes (with smaller estimated blood-to-air partition coefficients; approaching 10) are thought to exchange mostly in the alveoli. Exclusion of the first three exhalations from the analysis led to a median CV (IQR) of $6.7 \%$ (5.5\%) for the said classes of aldehydes. We found that such intra-subject variability is in general much lower than inter-subject variability (median relative differences between subjects $48.2 \%$ ), suggesting that the system is suitable to capture such differences. No batch effect due to sampling date was observed, overall suggesting that the intra-subject
\end{abstract}

Published in the topical collection Young Investigators in (Bio-)Analytical Chemistry with guest editors Erin Baker, Kerstin Leopold, Francesco Ricci, and Wei Wang.

Kapil Dev Singh and Georgi Tancev contributed equally to this work.

Electronic supplementary material The online version of this article (https://doi.org/10.1007/s00216-019-01764-8) contains supplementary material, which is available to authorized users.

Pablo Sinues

pablo.sinues@unibas.ch

1 University Children's Hospital Basel, University of Basel, Spitalstr. 33, 4056 Basel, Switzerland
2 Department of Biomedical Engineering, University of Basel, Gewerbestr. 14, 4123 Allschwil, Switzerland

3 Fossil Ion Technology S.L., Calle la Gitanilla 17, 29004 Malaga, Spain 
variability measured for these series of aldehydes was biological rather than technical. High correlations found among the series of aldehydes support this notion. Finally, recommendations for breath sampling and analysis for SESI-HRMS users are provided with the aim of harmonizing procedures and improving future inter-laboratory comparisons.

Keywords Breath metabolomics - Fatty aldehydes - Secondary electrospray ionization high-resolution mass spectrometry Oxidative stress $\cdot$ Standardization procedures $\cdot$ Variability

\section{Introduction}

Mass spectrometry is a pivotal technique in clinical chemistry laboratories and will continue its expansion to support clinical decision-making [1]. One of such potential future applications is the analysis of exhaled breath metabolites for clinical diagnosis and therapeutic monitoring [2]. However, such an endeavor requires standardized protocols, performed in multicenter studies leading to conclusive evidence, before regulatory authorities can approve a clinical test. In this regard, transitioning from promising research results to concrete clinical applications proves to be a challenge, leading to few routinely used clinical breath tests [3].

A number of analytical techniques have emerged over the last five decades, aiming to address this challenge, being the earliest one gas chromatography-mass spectrometry (GC-MS) $[4,5]$. GC-MS and its improved modern variants such as $\mathrm{GC} \times \mathrm{GC}$-Time of flight remain to be the workhorse platform capable of mapping the yet largely unknown breath metabolome [6]. However, one important limitation of GC-MS is the requirement of sample preparation, which leads to lengthy analyses and poses at the same time additional difficulties to standardize procedures and to preserve chemically uncompromised breath specimens [7]. Since breath constitutes a virtually unlimited source of information, real-time techniques such as proton-transfer-reaction mass spectrometry (PTR-MS) [8] and selected-ion flow-tube mass spectrometry (SIFT-MS) [9] emerged to conveniently capture this information. Such convenient online monitoring of exhaled metabolites is obviously of great advantage. However, it comes at the price of limited sensitivity - as no sample pre-concentration is possible-and limited selectivity-as no chromatographic separation prior to mass analysis is possible. A third realtime mass spectrometric alternative is secondary electrospray ionization-mass spectrometry (SESI-MS) [10]. In contrast to PTR-MS and SIFT-MS, ionization of exhaled metabolites takes place at atmospheric pressure in SESI-MS. The benefit of doing so is twofold: (i) the ionization probability increases with pressure [11] and (ii) it allows to conveniently interface the ionization stage with virtually any pre-existing atmospheric pressure ionization mass analyzer, including ultra-highresolution $(>100,000)$ MS such as Orbitrap. This results in sensitive and selective, yet real-time, analysis of trace vapor species. As a result, despite being the most recently proposed mass spectrometric alternative for real-time gas analysis, it is steadily gaining interest across different research groups [10, 12-26]. However, most of the published SESI-MS studies rely on lab-built instrumentation, making it difficult to standardize procedures for this technique. Following ongoing efforts to standardize exhaled breath collection and subsequent analysis for other analytical platforms [27-34], we present here a series of instrumental developments aiming to standardize breath analysis procedures and to provide recommendations for SESI-HRMS users interested in breath analysis. To do so, we characterized a series of new instrumentation with a focus on a panel of three classes of exhaled aldehydes.

\section{Material and methods}

We investigated the exhaled breath composition of healthy subjects by SESI-HRMS. The breath analysis platform consisted of three main components. The first one was a newly developed interface (Exhalion, FIT, Spain), which measures $\mathrm{CO}_{2}(\%)$, pressure drop (mbar), exhalation flow rate (L/min), and exhaled volume $(\mathrm{L})$ in real time to guide the exhalation maneuver. Downstream, the exhaled breath is ionized in an ion source (Super SESI, FIT, Spain). Ionized breath metabolites were then analyzed in real time by a high-resolution mass spectrometer $(\mathrm{Q}$ Exactive Plus, Thermo Fisher Scientific, Germany). Figure 1 a shows a picture of the breath analysis platform.

\section{Exhalation maneuver monitoring and guiding (Exhalion)}

The breath interface Exhalion was constructed with the aim of assisting in the control and reproducibility of exhalation maneuver. Exhalion consists of the following elements: a disposable standard antibacterial/antiviral medical grade filter. In this study, commercially available spirometry filters (MicroGard ${ }^{\mathrm{TM}}$, Vyaire Medical, USA; $3 \mathrm{~cm}$ ID; filters $99.98 \%$ of bacteria and $99.92 \%$ of viruses) were used as a mouthpiece. Downstream, the filter is connected to an autoclavable interface, housing a calibrated flow restriction. By measuring the pressure drop through the calibrated restriction (range 0 to 20 mbar, accuracy $2.5 \%$, precision 0.1 mbar), Exhalion determines the flow rate (range 0 to $15 \mathrm{~L} / \mathrm{min}$, accuracy $2.5 \%$ ), and total exhaled volume (the latter is automatically estimated by detecting the onset of the exhalation and integrating flow rate over time). Capnography data is measured side-stream (range 0 to $20 \%$, accuracy $5 \%$ of the reading), with 


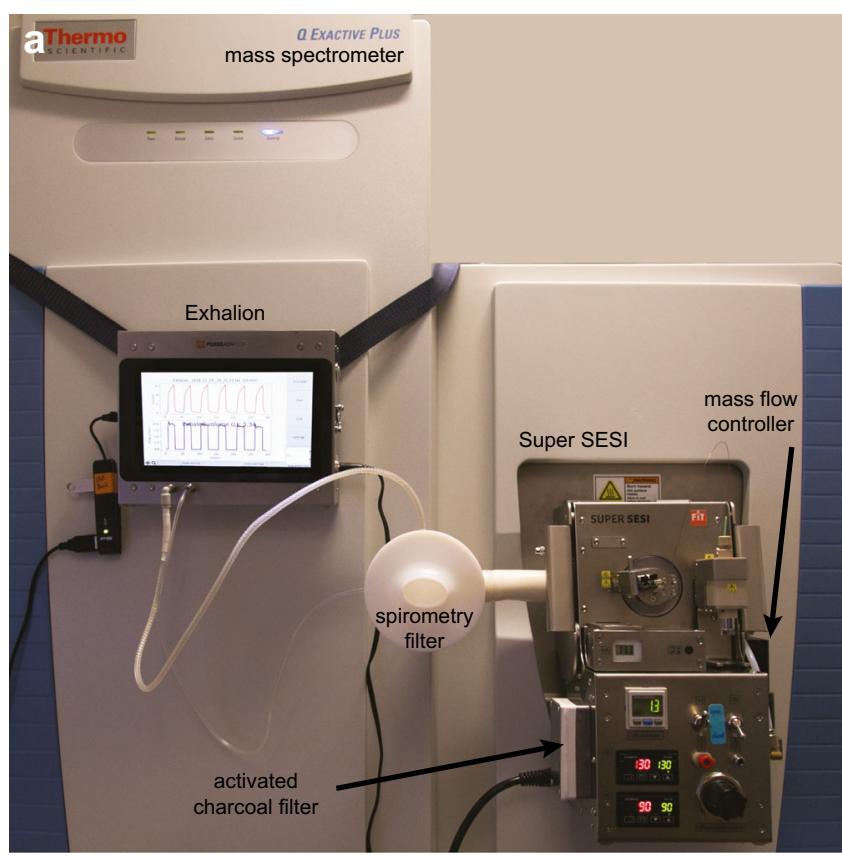

Fig. 1 Real-time breath analysis using SESI-HRMS. a SESI-HRMS analytical platform located in a clinical setting (University Children's Hospital Basel) dedicated for real-time breath analysis. The system features three main elements: (i) exhalation interface, which provides feedback to the participants on the exhalation maneuver; (ii) ion source, which efficiently ionizes exhaled metabolites, and (iii) high-resolution mass

an approximate flow rate of $0.5 \mathrm{~L} / \mathrm{min}$. Absolute pressure measurement is also integrated and is used to compensate for the effect of barometric variations on $\mathrm{CO}_{2}$ and flow readings. Time and other parameters are measured at a rate of $1.5 \mathrm{~Hz}$, and stored in a text file. Finally, a main module, incorporating a touch screen, a micro-computer, all sensors, and a dedicated firmware to run autonomously, is used to process all the data from flow restriction and capnograph in real time. All routines to seamlessly calibrate the sensors are integrated into the firmware. The main module and the flow restriction interface are connected with two tubes (1/8" OD, for $\mathrm{CO}_{2}$ and pressure measurement). Nafion tubing was used to prevent condensation. The dead volume of the side-stream tubing and the sensors was below $5 \mathrm{~cm}^{3}$, which provides an upper limit for the $\mathrm{CO}_{2}$ reading delay of $0.5 \mathrm{~s}$. The total dead volume was dominated by the mouthpiece filter, as Exhalion was designed to minimize this contribution. The Exhalion device was connected downstream with the ionization device (Super SESI).

\section{Secondary electrospray ionization (Super SESI)}

The Super SESI source was optimized for breath analysis and integrates all components required to control the ionization of the sample flow. A fraction of the total exhaled flow is passed to the ionizer, which features a sampling line connected to an ionization chamber whereby a nano-electrospray $(0.1 \%$ ammonium formate in water) ionizes the metabolites present in breath. We used

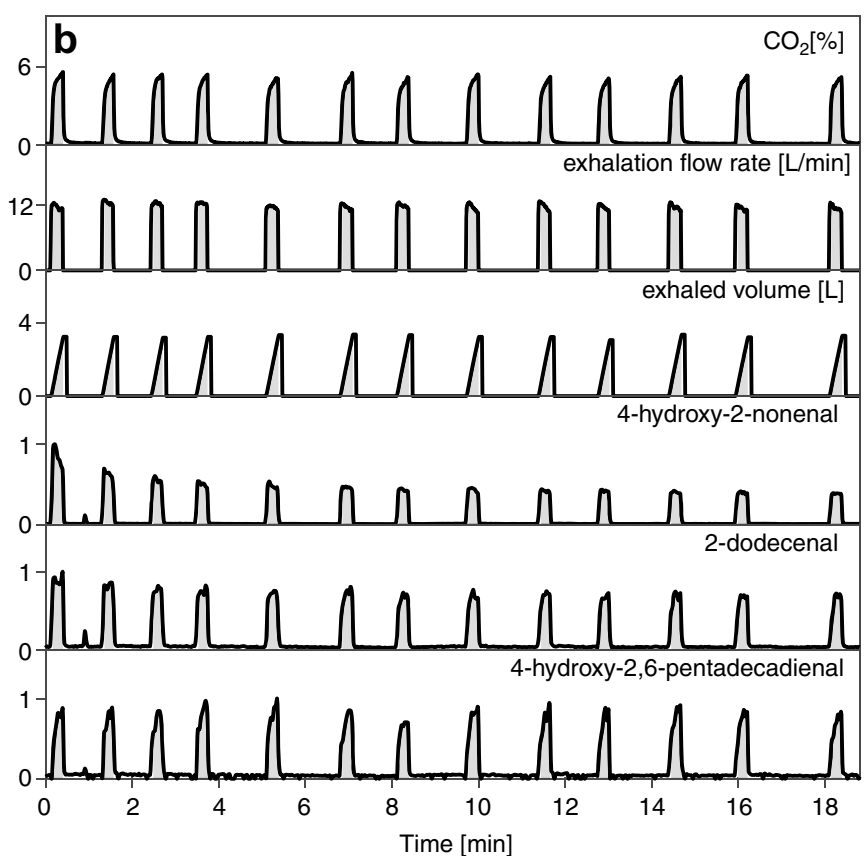

spectrometer. b Real-time analysis by simultaneous monitoring of $\mathrm{CO}_{2}$, physical exhalation parameters (exhalation flow rate and exhaled volume), and relative intensities of three representative aldehydes from one experiment. 13 consecutive exhalations within 20 min for one subject are shown (see ESM Fig. S4 for zoomed-in view of the first exhalation).

a 20- $\mu \mathrm{m}$ ID TaperTip (New Objective, USA) silica capillary emitter. The Super SESI pressure was set to 1.3 bar to drive the liquid through the capillary. The steady-state reading of the nanoamperemeter indicated that a stable spray was formed (typically $130 \mathrm{nA}$ ). The sampling line temperature was set to $130{ }^{\circ} \mathrm{C}$ and the ion chamber temperature was set to $90{ }^{\circ} \mathrm{C}$. In addition, the sampling line and the ionization chamber core were silica-coated to minimize analyte adsorption onto the system walls. Super SESI uses a flow of clean nitrogen (filtered through a built-in activated charcoal filter) to sweep the ionizer when there is no sample input. It was set to provide an excess of $0.4 \mathrm{~L} / \mathrm{min}$ over the flow ingested by the mass spectrometer (precise reading and control of this is integrated into the Super SESI). The exhaust mass flow controller was then set to $0.7 \mathrm{~L} / \mathrm{min}$ so that the fraction of breath entering the ionizer was fixed at $0.3 \mathrm{~L} / \mathrm{min}$ regardless of potential exhalation pressure fluctuations. The dead volume of the sample line and the ionizer was approximately $10 \mathrm{~cm}^{3}$. At this flow, the time required for breath to reach and sweep the ionizer is $2 \mathrm{~s}$.

\section{High-resolution mass spectrometry (Q Exactive Plus)}

The Super SESI source was directly coupled to the Q Exactive Plus MS and was recognized as an ESI source (sheath gas flow rate 60 , auxiliary gas flow rate 2 , spray voltage $3.5 \mathrm{kV}$, capillary temperature $275{ }^{\circ} \mathrm{C}$, and S-lens RF level 55.0). The MS was operated directly via Q Exactive Tune software (version 2.9) in 
full MS mode (polarity positive, scan range 100 to $400 \mathrm{~m} / \mathrm{z}$, microscans 4 , ACG target $10^{6}$, and maximum injection time $500 \mathrm{~ms}$ ) with a resolution of 140,000 (at $\mathrm{m} / \mathrm{z}$ 200). The MS was externally calibrated on a weekly basis using a commercially available calibration solution (Pierce ${ }^{\mathrm{TM}}$ Triple Quadrupole, extended mass range) and internally calibrated by enabling lock masses $(\mathrm{m} / \mathrm{z}$ 149.02332, 279.15909, 355.06993, 371.10123, and 391.28429), which correspond to common background mass spectrometric contaminants $[35,36]$.

\section{Subjects}

Three male and one female healthy subjects ( $33 \pm 8$ years, mean $\pm \mathrm{SD}$ ) were enrolled in the study, each subject provided at least 49 exhalations. All measurements were performed during weekdays at any given time between 8 a.m. and 6 p.m. Fig. S1 (see Electronic Supplementary Material, ESM) shows the measurement scheduling distribution for all participants, indicating no significant bias towards a specific time window for any given subject. The sample size and number of replicates resulted from estimating the within-subject standard deviation, following the approach described by Bland and Altman [37]. Shortly, the precision with which one can estimate withinsubject standard deviation depends on both the number of subjects and the number of observations per subject. Details are described in the ESM (Table S1). The subjects provided prolonged exhalations, whereby the subjects inspired to total lung capacity and expired at a constant flow rate. This expiration maneuver was repeated at least six consecutive times with breaks of at least $10 \mathrm{~s}$ in-between replicate exhalations. Typically, the total exhaled volume per exhalation was $3 \mathrm{~L}$. To guide the maneuver, the subjects could monitor in real time their $\mathrm{CO}_{2}$ level, exhalation flow rate, and exhaled volume on the Exhalion touch screen. Fig. S2 (see ESM) shows a picture of how a subject would perform the breath test.

\section{Data analysis}

Raw data from the MS and Exhalion device were exported and processed using MATLAB (version 2018a, MathWorks Inc., USA). Briefly, raw MS data were converted into mzXML file format using ProteoWizard's msConvertGUI [38]. Afterwards, each spectrum from all files was aligned and calibrated using the RAFFT algorithm implemented in MATLAB [39]. Then mspeaks and ksdensity functions of MATLAB were used to appropriately pick and extract the final feature list of 2,255 features. Molecular formulae were generated based on the accurate mass by considering $\mathrm{C}, \mathrm{H}, \mathrm{N}$, and $\mathrm{O}$ [40]. A number of studies suggest using $\mathrm{CO}_{2}$ - and volume-controlled sampling maneuvers as a standardization procedure [34, 41-44]. Following the recommendations to use this physiological parameter to normalize breath analysis data, we normalized signal intensities by considering exhalation windows where the $\mathrm{CO}_{2}$ concentrations rose above $3 \%$. In particular, we computed the signal intensity for each of these 2,255 features during each exhalation by using the time corresponding to $3 \%$ or more of the $\mathrm{CO}_{2}$ signal (from Exhalion) to define a single exhalation event. Finally, the integrated area under the curve (AUC) for all features was normalized by the exhaled volume in the exhalation (calculated by integrating the flow over time in a particular exhalation from Exhalion data). We will henceforth refer to this normalized AUC as breath-signal.

For Fig. 2 and Figs. S6-S8 (see ESM), we first normalized the breath-signal of metabolites from each experiment (containing 6 exhalations) to the maximum. Then, normalized breath-signals of metabolites were averaged across different experiments to obtain the final "mean normalized breathsignal" of metabolites for each subject along with their $95 \%$ confidence interval (CI).

Intra-subject variability for each feature was estimated by calculating the coefficient of variation ( $\mathrm{CV}$, expressed as percentage) of the replicate exhalations (this analysis led to Table 1). Inter-subject variability was evaluated by performing one-way analysis of variance (ANOVA; grouped by subjects), followed by a multiple comparison (post hoc) test, using the Bonferroni method, to determine whether pairs of group means were significantly different (this analysis led to Table 2).

\section{Gas standard generation (ReGaS2)}

To monitor the stability of the ionization, a reactive gas standard generator (ReGaS2) developed by the Swiss Federal Institute of Metrology (METAS) [45], was used. This device releases a flow with stable concentrations of trace gases and can be used to standardize gas sensors. In our case, $\beta$-pinene at a concentration of $92.7 \mathrm{ppb}$ in air was used as target vapor (carrier flow of $1 \mathrm{~L} / \mathrm{min}$ and dilution flow of $0.5 \mathrm{~L} / \mathrm{min}$ at an oven temperature of $41^{\circ} \mathrm{C}$ ).

\section{Results and discussion}

\section{Technical variability measured using $\beta$-pinene vapors}

Before discussing the biological variability measured in human breath, we gauged the typical technical variability to be expected for our SESI-HRMS system. In order to do so, we infused a continuous stream of air seeded with $92.7 \mathrm{ppb}$ of $\beta$ pinene, simulating an exhalation maneuver. Upon injection of the standard, the mass spectrum was dominated by the expected protonated $\beta$-pinene at $m / z$ 137.1326 $\left(\mathrm{C}_{10} \mathrm{H}_{17}\right)$, along with some oxidized species $\left(\mathrm{C}_{10} \mathrm{H}_{15} \mathrm{O}\right.$ and $\mathrm{C}_{10} \mathrm{H}_{17} \mathrm{O}_{2}$; ESM Fig. $\mathrm{S} 3$ ). SESI-MS is known to detect trace species down to the 


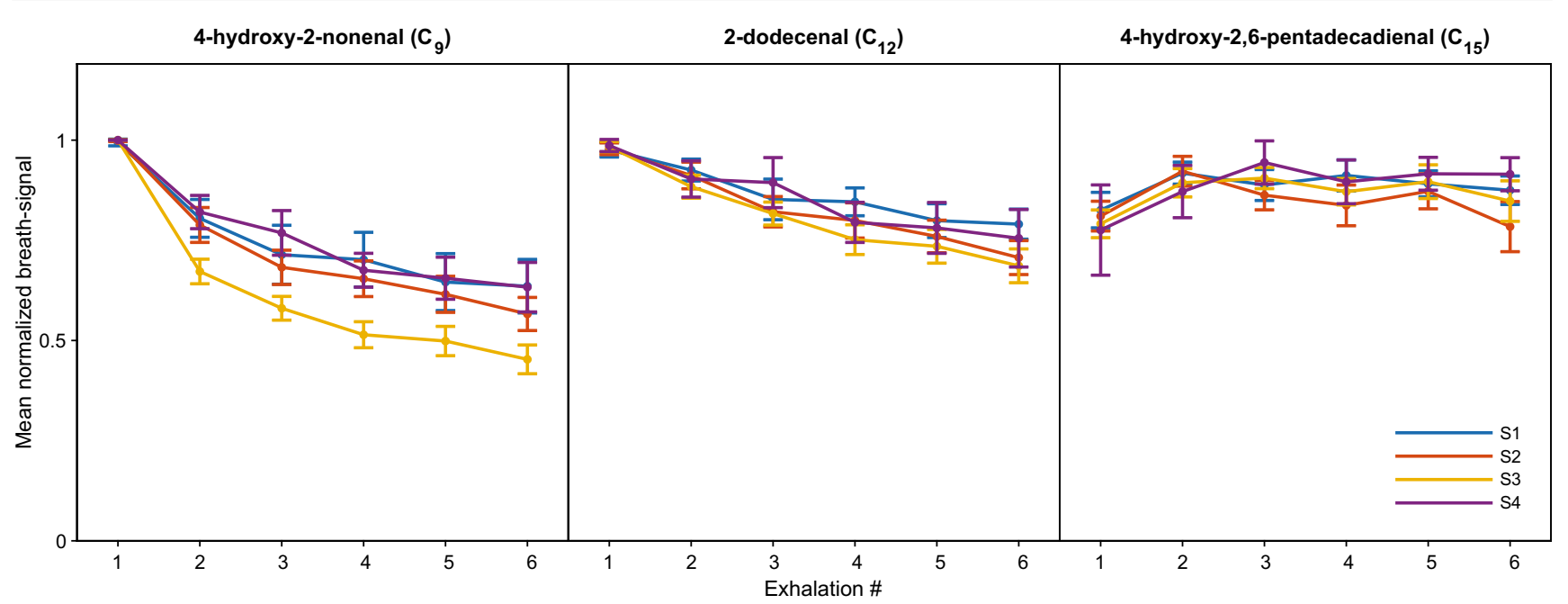

Fig. 2 Aldehydes show a subject-independent and molecule-dependent exhalation pattern. Data shown is the mean normalized breath-signal with errors bars representing $95 \%$ CIs for three selected aldehydes from four subjects (denoted as S1-S4) in 104 experiments as a function of exhalation number. Lighter species show a systematic decaying trend across consecutive exhalations, which is subject independent.

Orbitrap mass analyzer. Because the dynamic range of our mass analyzer is five orders of magnitude (signal intensity

$92.7 \mathrm{ppb}$ of $\beta$-pinene nearly saturated the detector of the

Table 1 Intra-subject variability in the breath-signal for the series of aldehydes studied in this work. The median and IQR values of the CVs (expressed as percentage) measured for the four subjects for the 27 aldehydes studied are listed; $D B E$ double bond equivalent

\begin{tabular}{|c|c|c|c|c|c|c|c|c|c|c|c|c|}
\hline \multirow[t]{3}{*}{$m / z\left([\mathrm{M}+\mathrm{H}]^{+}\right)$} & \multicolumn{4}{|l|}{ Metabolite } & \multicolumn{8}{|c|}{ Coefficient of variation (\%) } \\
\hline & \multirow[b]{2}{*}{$\begin{array}{l}\text { Formula } \\
\text { (M) }\end{array}$} & \multirow[b]{2}{*}{ Name } & \multirow[b]{2}{*}{ DBE } & \multirow[b]{2}{*}{$\begin{array}{l}\text { Mass error } \\
(\mathrm{ppm})\end{array}$} & \multicolumn{2}{|c|}{$\mathrm{S} 1(N=25)$} & \multicolumn{2}{|c|}{$\mathrm{S} 2(N=29)$} & \multicolumn{2}{|c|}{$\mathrm{S} 3(N=37)$} & \multicolumn{2}{|c|}{$\mathrm{S} 4(N=13)$} \\
\hline & & & & & Median & IQR & Median & $\mathrm{IQR}$ & Median & IQR & Median & IQR \\
\hline 143.1066 & $\mathrm{C} 8 \mathrm{H} 14 \mathrm{O} 2$ & 4-Hydroxy-2-octenal & 2 & -0.32 & 6.2 & 6.7 & 7.5 & 4.2 & 6.3 & 6.0 & 4.3 & 2.7 \\
\hline 157.1223 & $\mathrm{C} 9 \mathrm{H} 16 \mathrm{O} 2$ & 4-Hydroxy-2-nonenal & 2 & 0.16 & 6.8 & 6.0 & 8.7 & 4.6 & 7.8 & 7.4 & 4.9 & 2.4 \\
\hline 171.1379 & $\mathrm{C} 10 \mathrm{H} 18 \mathrm{O} 2$ & 4-Hydroxy-2-decenal & 2 & -0.15 & 7.3 & 5.3 & 7.5 & 4.8 & 7.3 & 5.8 & 4.3 & 2.2 \\
\hline 185.1537 & $\mathrm{C} 11 \mathrm{H} 20 \mathrm{O} 2$ & 4-Hydroxy-2-undecenal & 2 & 0.30 & 6.8 & 4.8 & 7.5 & 4.2 & 6.9 & 6.5 & 4.4 & 3.8 \\
\hline 199.1694 & $\mathrm{C} 12 \mathrm{H} 22 \mathrm{O} 2$ & 4-Hydroxy-2-dodecenal & 2 & 0.58 & 7.6 & 8.5 & 8.0 & 4.7 & 7.7 & 6.6 & 4.6 & 3.6 \\
\hline 213.1851 & $\mathrm{C} 13 \mathrm{H} 24 \mathrm{O} 2$ & 4-Hydroxy-2-tridecenal & 2 & 0.68 & 7.6 & 6.7 & 7.9 & 4.7 & 6.5 & 5.5 & 4.7 & 2.5 \\
\hline 227.2005 & $\mathrm{C} 14 \mathrm{H} 26 \mathrm{O} 2$ & 4-Hydroxy-2-tetradecenal & 2 & -0.11 & 5.6 & 4.5 & 7.2 & 3.9 & 6.6 & 5.6 & 5.5 & 4.0 \\
\hline 241.2162 & $\mathrm{C} 15 \mathrm{H} 28 \mathrm{O} 2$ & 4-Hydroxy-2-pentadecenal & 2 & -0.11 & 4.8 & 5.1 & 6.1 & 5.0 & 6.1 & 3.8 & 5.7 & 3.2 \\
\hline 255.2319 & $\mathrm{C} 16 \mathrm{H} 30 \mathrm{O} 2$ & 4-Hydroxy-2-hexadecenal & 2 & -0.02 & 6.2 & 5.0 & 5.1 & 5.0 & 6.0 & 5.8 & 7.1 & 3.4 \\
\hline 127.1118 & $\mathrm{C} 8 \mathrm{H} 14 \mathrm{O}$ & 2-Octenal & 2 & 0.07 & 6.5 & 3.8 & 6.3 & 4.2 & 7.3 & 8.5 & 7.4 & 6.5 \\
\hline 141.1275 & C9H16O & 2-Nonenal & 2 & 0.42 & 7.4 & 5.2 & 7.5 & 3.4 & 7.1 & 6.3 & 5.8 & 3.9 \\
\hline 155.1429 & $\mathrm{C} 10 \mathrm{H} 18 \mathrm{O}$ & 2-Decenal & 2 & -0.66 & 6.0 & 7.0 & 6.6 & 5.4 & 6.0 & 5.9 & 4.0 & 4.7 \\
\hline 169.1587 & $\mathrm{C} 11 \mathrm{H} 20 \mathrm{O}$ & 2-Undecenal & 2 & -0.01 & 6.6 & 7.0 & 8.1 & 4.2 & 7.4 & 5.6 & 5.7 & 5.3 \\
\hline 183.1744 & $\mathrm{C} 12 \mathrm{H} 22 \mathrm{O}$ & 2-Dodecenal & 2 & 0.49 & 6.7 & 4.9 & 7.7 & 5.2 & 6.9 & 6.3 & 5.4 & 2.2 \\
\hline 197.1901 & $\mathrm{C} 13 \mathrm{H} 24 \mathrm{O}$ & 2-Tridecenal & 2 & 0.56 & 6.5 & 7.3 & 7.0 & 3.5 & 7.5 & 7.0 & 5.5 & 4.6 \\
\hline 211.2055 & $\mathrm{C} 14 \mathrm{H} 26 \mathrm{O}$ & 2-tetradecenal & 2 & -0.53 & 7.5 & 5.7 & 7.8 & 4.9 & 6.8 & 5.9 & 7.1 & 4.9 \\
\hline 225.2213 & $\mathrm{C} 15 \mathrm{H} 28 \mathrm{O}$ & 2-Pentadecenal & 2 & -0.09 & 7.6 & 7.7 & 7.8 & 4.1 & 7.4 & 5.2 & 6.8 & 5.0 \\
\hline 239.2369 & $\mathrm{C} 16 \mathrm{H} 30 \mathrm{O}$ & 2-Hexadecenal & 2 & -0.05 & 8.3 & 7.0 & 12.8 & 12.2 & 8.4 & 7.2 & 8.0 & 8.4 \\
\hline 141.0910 & $\mathrm{C} 8 \mathrm{H} 12 \mathrm{O} 2$ & 4-Hydroxy-2,6-octadienal & 3 & 0.25 & 5.4 & 5.8 & 7.3 & 3.6 & 5.7 & 4.8 & 4.5 & 3.0 \\
\hline 155.1066 & C9H14O2 & 4-Hydroxy-2,6-nonadienal & 3 & -0.62 & 5.4 & 7.6 & 7.7 & 3.8 & 6.7 & 6.5 & 5.3 & 2.8 \\
\hline 169.1223 & $\mathrm{C} 10 \mathrm{H} 16 \mathrm{O} 2$ & 4-Hydroxy-2,6-dodecadienal & 3 & 0.09 & 7.4 & 6.9 & 7.9 & 4.5 & 5.8 & 5.1 & 5.4 & 3.8 \\
\hline 183.1380 & $\mathrm{C} 11 \mathrm{H} 18 \mathrm{O} 2$ & 4-Hydroxy-2,6-undecadienal & 3 & 0.46 & 7.1 & 6.3 & 7.8 & 3.5 & 7.7 & 5.7 & 4.5 & 3.0 \\
\hline 197.1537 & $\mathrm{C} 12 \mathrm{H} 20 \mathrm{O} 2$ & 4-Hydroxy-2,6-dodecadienal & 3 & 0.58 & 7.6 & 5.5 & 7.7 & 4.5 & 5.3 & 4.3 & 4.8 & 3.0 \\
\hline 211.1692 & $\mathrm{C} 13 \mathrm{H} 22 \mathrm{O} 2$ & 4-Hydroxy-2,6-tridecadienal & 3 & -0.41 & 7.0 & 7.3 & 7.7 & 5.0 & 6.0 & 5.6 & 5.1 & 4.3 \\
\hline 225.1849 & $\mathrm{C} 14 \mathrm{H} 24 \mathrm{O} 2$ & 4-Hydroxy-2,6-tetradecadienal & 3 & -0.07 & 6.6 & 6.5 & 6.6 & 5.3 & 6.0 & 6.2 & 5.1 & 3.4 \\
\hline 239.2005 & $\mathrm{C} 15 \mathrm{H} 26 \mathrm{O} 2$ & 4-Hydroxy-2,6-pentadecadienal & 3 & -0.11 & 7.4 & 6.6 & 11.7 & 13.5 & 5.8 & 4.7 & 5.3 & 6.2 \\
\hline 253.2162 & $\mathrm{C} 16 \mathrm{H} 28 \mathrm{O} 2$ & 4-Hydroxy-2,6-hexadecadienal & 3 & -0.02 & 8.1 & 9.2 & 4.6 & 4.4 & 6.3 & 5.5 & 5.6 & 3.8 \\
\hline
\end{tabular}




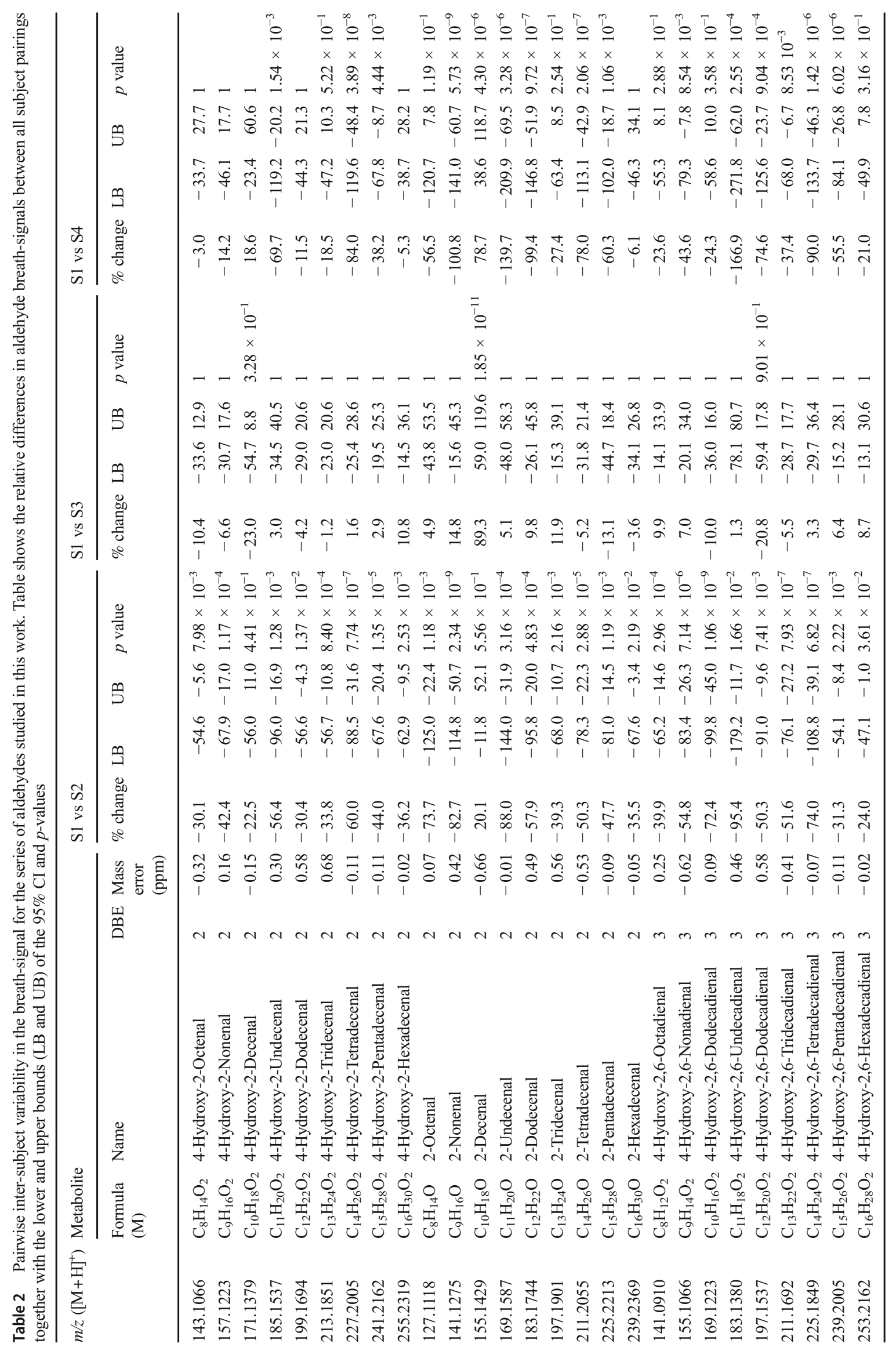




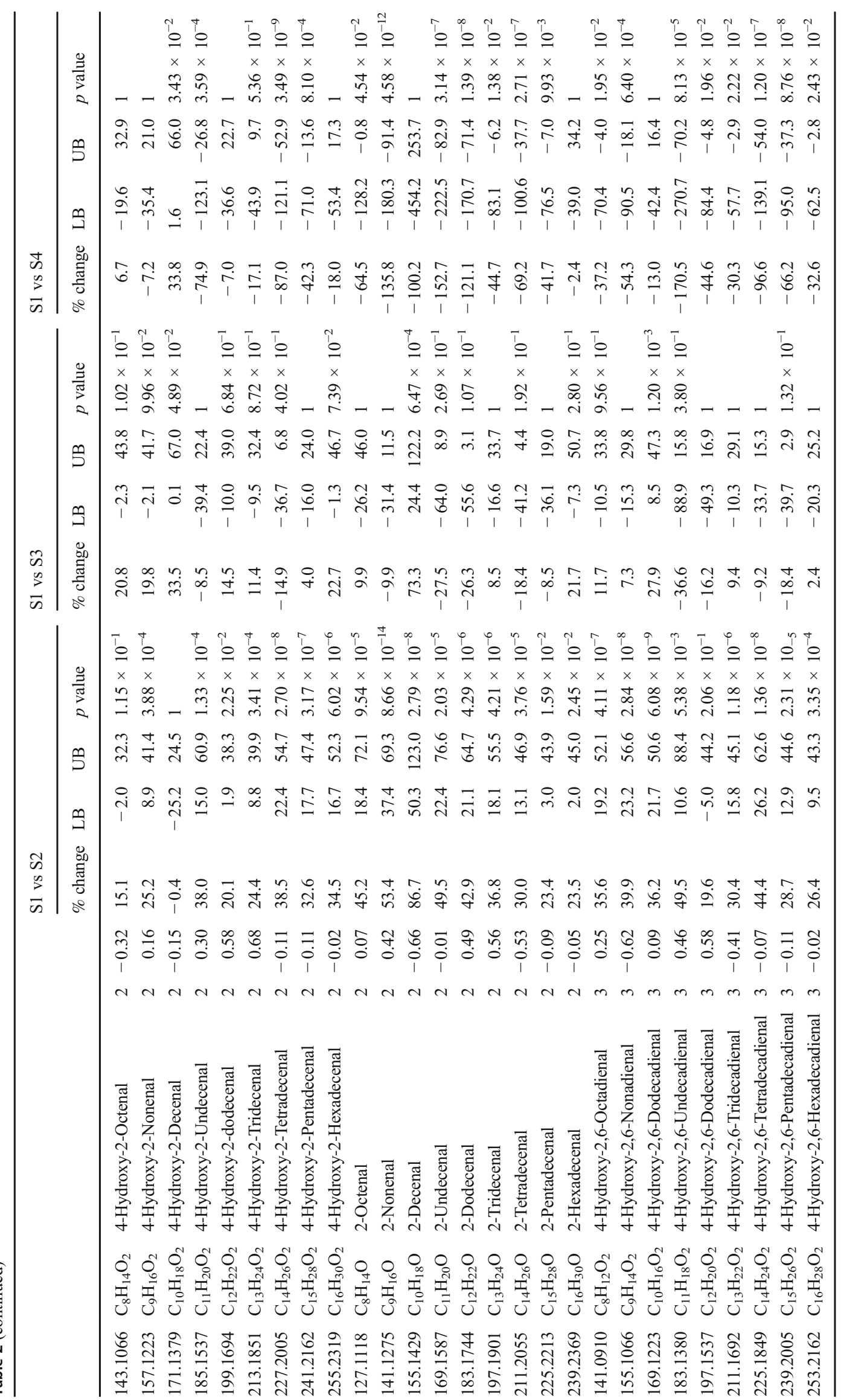


$10^{4}-10^{9}$ a.u.), the limit of detection is expected to be at around $1 \mathrm{ppt}$, which is consistent with previous SESI-MS quantification studies [46]. When we started the delivery of $\beta$-pinene, the signal of the protonated analyte raised sharply to reach a plateau. We measured the stability of the signal intensity detection during $1 \mathrm{~h}$. When the delivery of $\beta$-pinene was stopped, the signal intensity dropped abruptly to baseline level, indicating no carryover effects, at least for this particular compound (inset Fig. S3, see ESM). The CV of $\beta$-pinene signal intensity during an hour of continuous delivery of the vapor was found to be $2.3 \%$. We therefore conclude that technical CVs within 3\% are to be expected for our SESI-HRMS platform.

\section{Replicate exhalations: intra- and inter-subject variability}

In total, the four participants provided 648 exhalations $(n=$ 171 for subject $1, n=174$ for subject $2, n=225$ for subject 3 and $n=78$ for subject 4$)$. These measurements were subdivided into 104 single experiments $(N=25$ for subject $1, N=29$ for subject $2, N=37$ for subject 3 , and $N=13$ for subject 4) each containing 6 to 13 exhalations (replicates) performed within 10 to $20 \mathrm{~min}$. The aim was to examine the variability across these replicates, considering that the technical variability, as mentioned above, was found to be in the range of $3 \%$. Figure $1 \mathrm{~b}$ shows one such representative experiment whereby a subject provided 13 consecutive exhalations during 19 min (ESM Fig. S4 shows a zoomed-in view of the first exhalation, where the time traces can be inspected in greater detail).

The vast majority of the features typically detected by SESI-HRMS in human breath remain to be positively identified. However, over the last years, we have made a substantial effort to systematically identify the molecular structure for some of these metabolites by combining real-time breath MS/MS analysis and UPLC-MS/MS analysis of exhaled breath condensate [47-53]. Given the clinical importance of aldehydes, as potential surrogates of oxidative stress [54-59], we will concentrate in discussing our findings for a series of three classes of fatty aldehydes [48]: 4-hydroxy-2-alkenals $\left(\mathrm{C}_{x} \mathrm{H}_{2 x-}{ }_{2} \mathrm{O}_{2}\right), 2$-alkenals $\left(\mathrm{C}_{x} \mathrm{H}_{2 x-2} \mathrm{O}\right)$, and 4-hydroxy-2,6alkadienals $\left(\mathrm{C}_{x} \mathrm{H}_{2 x}-{ }_{4} \mathrm{O}_{2}\right)$ with chain lengths ranging from $\mathrm{C}_{8}$ to $\mathrm{C}_{16}$. These 27 representative aldehydes were used as benchmarking metabolites. For reference, Fig. $1 \mathrm{~b}$ shows the time traces of three such representative exhaled aldehydes and Fig. S5 (see ESM) shows the time traces for the 27 aldehydes of interest from the same experiment. The gray areas in Fig. 1 b and Fig. S4 (see ESM) represent the time windows whereby $\mathrm{CO}_{2}$ levels were above $3 \%$.

Visual inspection of $\mathrm{CO}_{2}$ and exhalation parameters from Fig. 1b suggests a high repeatability across replicate measurements. Indeed, computed mean \pm SD for this particular experiment yielded a $\mathrm{CO}_{2}$ level of $4.7 \pm 0.1 \%$, an exhalation flow rate of $11.7 \pm 0.3 \mathrm{~L} / \mathrm{min}$ and an exhaled volume of $2.6 \pm$ $0.1 \mathrm{~L}$ (i.e., excluding $0.5-0.6 \mathrm{~L}$ of breath not containing at least $3 \%$ of $\mathrm{CO}_{2}$ ) for the considered windows. Median $\mathrm{CVs}$ (IQRs) for $\mathrm{CO}_{2}$, exhalation flow rate, and exhaled volume based on all 104 experiments were $3.2 \%(1.5 \%), 3.1 \%$ $(1.9 \%)$, and $5.0 \%(4.6 \%)$, respectively. The overall picture for the aldehydes was somehow more complex. While 4-hydroxy-2,6-pentadecadienal in Fig. 1 b shows a relatively constant behavior across all exhalations (akin to $\mathrm{CO}_{2}$ ), 2dodecenal drops over time during consecutive exhalations and the decay is even more pronounced for 4-hydroxy-2nonenal, whose signal intensity decays by $\sim 35 \%$ during the first three exhalations, to then reach a steady state. Interestingly, we observed this behavior systematically for these particular molecules among all participants. Figure 2 shows the mean normalized breath-signal (see "Material and methods" for details) and the corresponding 95\% CI from all experiments for the four participants as a function of exhalation number for the three selected representative compounds shown in Fig. 1 b. It clearly shows that the dynamics for each compound are subject independent and, interestingly, seem to depend on the aldehyde chain length. For example, signal intensity drops between the first and the sixth exhalation for 4-hydroxy-2-nonenal is around 50\%, for 2-dodecenal the drop is around $30 \%$, whereas for 4-hydroxy-2,6-pentadecadienal signal intensity remains stable (or even increases after the first exhalation). This trend was systematically observed for all the aldehydes from the three classes (ESM Figs. S6-S8).

\section{Location within the respiratory system where the gas exchange occurs may explain the molecule-dependent exhalation traces}

The signal intensity decaying behavior as a function of chain length can be rationalized by the dependency with Ostwald blood-air partition coefficient $\left(\lambda_{b: a}\right)$, which is the most important factor in determining the location within the respiratory system where the gas exchange occurs [60]. Soluble gases with $\lambda_{b: a}>100$ exchange almost exclusively within the airways (with the bronchial blood), whereas those with $10<\lambda_{b: a}$ $<100$ exchange partially in the airways and in the alveoli, and those with a $\lambda_{b: a}<10$ nearly exclusively exchange in the alveoli (with the pulmonary blood) [61]. Therefore, $\mathrm{CO}_{2}$ $\left(\lambda_{b: a}=3\right)$ exchanges in the alveoli [62]. Figure $1 \mathrm{~b}$ shows that the $\mathrm{CO}_{2}$ level does not decrease as the participant provides consecutive exhalations and this was the trend observed across all measurements. The same trend is observed for the longest aldehydes, which in turn have the lowest $\lambda_{b: a}$ from the series. The predicted $\lambda_{b: a}$ by Kramer et al. [63] suggests that, indeed, shorter aldehydes have a greater $\lambda_{b: a}$. For example, the predicted $\lambda_{b: a}$ for 2-hexenal was 111, therefore exchanges almost exclusively in the airways. In contrast, 2-undecenal 
has a predicted $\lambda_{b: a}=39$; hence, it exchanges partially in the airways and in the alveoli. It is expected that even longer aldehydes $\left(>\mathrm{C}_{14}\right)$, such as those studied in this work, will have a $\lambda_{b: a}$ approaching the critical value of 10 (i.e., almost exclusively exchanged in the alveoli). This trend can be observed in Fig. S9 (see ESM), which shows predicted $\lambda_{b: a}$ as a function of the number of carbon atoms from the aldehydes, based on data by Kramer et al. [63]. Thus, we hypothesize that the longest aldehydes studied here $\left(\mathrm{C}_{14}-\mathrm{C}_{16}\right)$ exchange exclusively in the alveoli, and for this reason show a similar behavior as $\mathrm{CO}_{2}$. In contrast, the smaller aldehydes exchange mainly in the airways, leading to a decrease during prolonged consecutive exhalations. For example, it has been estimated that ethanol, which has a high blood solubility $\left(\lambda_{b: a}=1,803\right)$, can show a $20 \%$ lower concentration than alveolar air after a complete prolonged exhalation [62]. Reinforcing this idea, we found that the signal intensity as a function of exhaled volume during a single exhalation, varies significantly depending on the aldehyde chain length and therefore on their $\lambda_{b: a}$. Figure 3 a displays signal intensity profiles of the aldehydes as a function of exhaled volume for a representative first and last exhalation in an experiment (same experiment as Fig. 1 b). It clearly shows how the $\mathrm{C}_{9}$ metabolites reach a maximum intensity at $\sim 0.7 \mathrm{~L}$ to then decrease. In contrast, the exhalation profile for the longest aldehydes $\left(\mathrm{C}_{12}\right.$ and $\left.\mathrm{C}_{15}\right)$ tends to increase systematically with exhaled volume (similarly to $\mathrm{CO}_{2}$ profiles). We hypothesize that, as the exhalation maneuver is

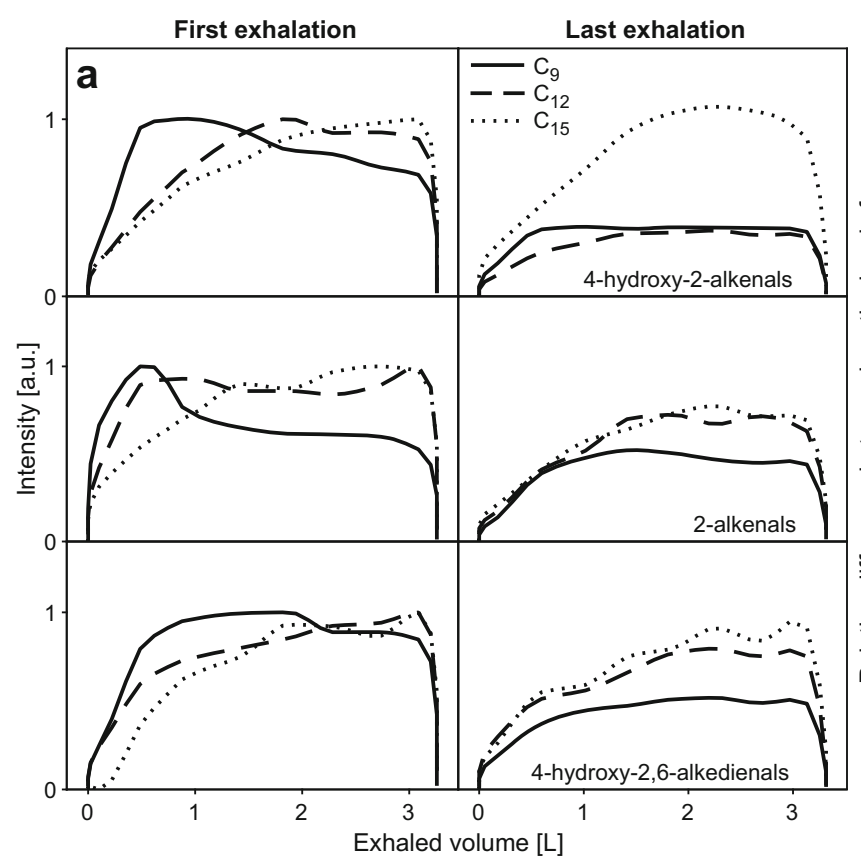

Fig. 3 Dependency of exhalation profile of breath metabolites with blood-to-air partition coefficient. a Exhalation profiles of short and long aldehydes as a function of exhaled volume is consistent with the hypothesis that the shorter aldehydes exchange mostly in the airways, while longer aldehydes exchange in the alveoli. 4-hydroxy-2-dodecenal shows a deviating pattern that may be caused by an interfering peak. b Relative repeated, the net influx towards bronchial circulation exceeds that outwards. Thus, the partial pressure cannot re-equilibrate in the short lapse in-between exhalations, leading to a constant non-linear decay across the repeated measurements. For 4hydroxy-2-dodecanal, we observed a deviation from the decaying pattern (Fig. 3 a and ESM Fig. S5). The underlying reason might be that this particular $\mathrm{m} / \mathrm{z}$ channel is dominated by an isomer of 4-hydroxy-2-dodecanal. It is important to note at this point that this is a limitation of SESI-HRMS, as discrimination of isomers is sacrificed by the possibility of performing real-time analysis.

In order to further connect the theoretical explanation as to why $\lambda_{b: a}$ ultimately modulates the decay in signal intensity due to gas exchange in the airways, Fig. $3 \mathrm{~b}$ (and ESM Fig. S10) shows the experimental average breath-signal difference between the last and first exhalation, as a function of predicted $\lambda_{b: a}$. These $\lambda_{b: a}$ values were estimated by fitting the $\lambda_{b: a}$ for all aldehydes reported by Kramer et al. [63] (ESM Fig. S9). It reveals a clear trend, whereby for the longest chain $\left(\mathrm{C}_{16}\right)$ the difference tends to increase during the repeated measurements. This is especially evident for 4-hydroxy-2hexadecenal (ESM Fig. S6). In contrast, as the chain length decreases (and thus $\lambda_{b: a}$ increases), the breath-signal difference decreases to finally reach a plateau of $\Delta-20 \%$ to $-40 \%$ at $\mathrm{C}_{11}$. The fact that this clear trend occurs in the transition boundaries between $10<\lambda_{b: a}<100$ suggests that indeed this may be due to the different regions of the respiratory

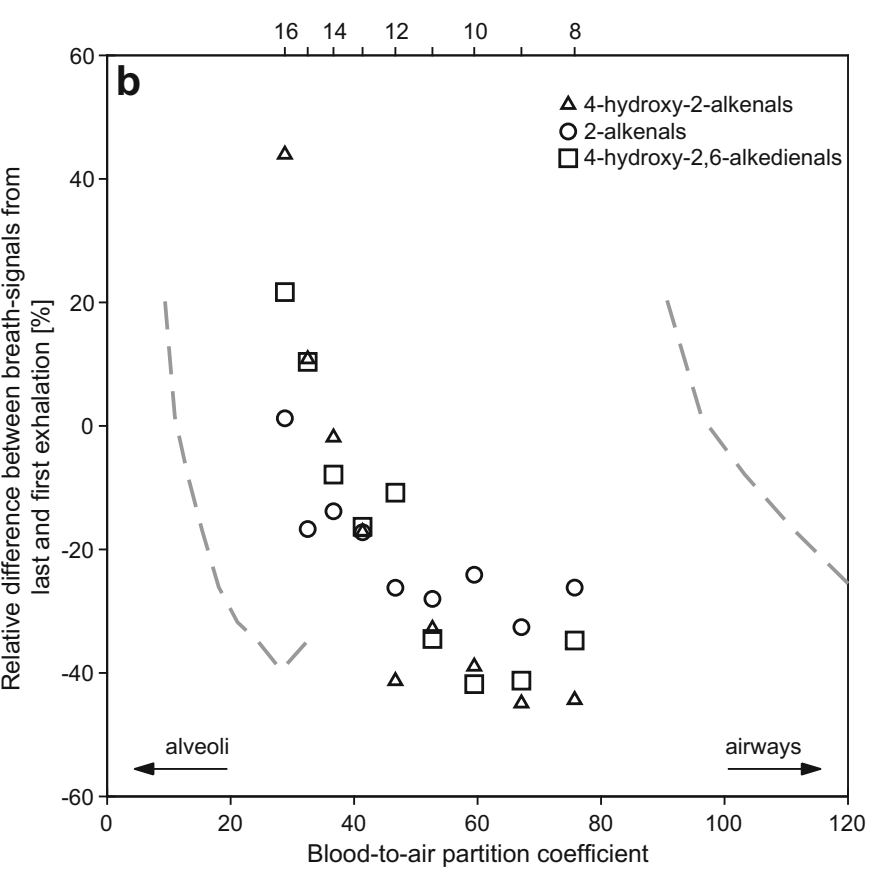

difference between breath-signals from last and first exhalation as a function of predicted blood-to-air partition coefficient. A number of carbon atoms for molecules are shown at the top and gray dashed curves shows the $95 \% \mathrm{CI}$ from $\lambda_{b: a}$ estimation. A large partition coefficient is associated with a strongly decaying pattern (also see ESM Fig. S10, with $x$-axis on $\log _{10}$ scale, showing the complete range for $95 \%$ CIs) 
system where these series of compounds exchange: from alveoli for $\mathrm{C}_{16}$ to airways for $\mathrm{C}_{8}$, with a mixed exchange situation for intermediate species. Further work is required to confirm this hypothesis and whether this could be further exploited to infer physiological information of the respiratory system, for example, complementing other tests such as the multiple-breath washout test to measure abnormal ventilation distribution between well- and poorly ventilated lung regions.

Despite that the first exhalation may reflect more accurately systemic concentrations for metabolites with high blood-air partition coefficients, we recommend to sample at least ten replicate exhalations and compute breath-signals considering only the last three exhalations, thus capturing the steady state. When doing so in the example shown in Fig. $1 \mathrm{~b}$, the median CV (IQR) for the 27 aldehydes was $4.1 \%$ (1.5\%), which approaches the technical variability of $\sim 3 \%$ measured with standard $\beta$-pinene vapors. However, for pediatric patients and patients suffering from respiratory diseases, this may prove difficult. For this reason, in order to determine an upper bound of expected variability, we have evaluated here the variability of breath metabolites across all subjects considering only six exhalations and excluded the first three maneuvers to the breath-signal for metabolites. When doing so, we found that the median CV (IQR) for the aldehydes studied here was 6.7\% (5.5\%). Table 1 lists the intra-subject CVs for the 27 aldehydes studied here.

\section{Flow dependency}

Some studies indicate that the exhalation maneuver itself can in some cases alter the metabolic profile, hence providing misleading results [32]. For this reason, we further investigated whether the exhalation flow rate of our protocol had an impact on the breath-signal of the exhaled metabolites. Flow resistance of the device was as low as $3 \mathrm{mbar} \times \min / \mathrm{L}$, mean \pm SD exhalation flow rates of all the experiments performed in this study $(N=104)$ was $10.6 \pm 0.9 \mathrm{~L} / \mathrm{min}$ (ESM Fig. S11) and typical exhaled volumes were in the order of $3 \mathrm{~L}$ (i.e., 15-20 s of exhalation). It is important to note that this maneuver is far less invasive and easy to perform than a classical spirometry, whereby the forced expiratory volume in one second $\left(\mathrm{FEV}_{1}\right)$ can typically be $4 \mathrm{~L}$ in adults. This implies exhalation flow rates around 25 times higher than the maneuver used in our experiments. It has been shown that such forced expiration maneuvers can lead to substantial changes in exhaled $\mathrm{CO}_{2}$ and other metabolites [32]. The fact that no significant changes in the $\mathrm{CO}_{2}$ levels were observed suggests that the maneuver does not induce hyperventilation [42]. In order to determine whether there was any dependency with the exhalation flow rate, we explored the impact of exhaling at two flow rates, one at the lower end and another one at the upper end of the distribution of exhalation flow rates measured for all participants (ESM Fig. S11). Figure 4 a shows the comparison of two measurements from the same subject at a lower flow rate $(9.8 \pm 0.1 \mathrm{~L} / \mathrm{min})$ and consecutively at a higher flow rate $(12.0$ $\pm 0.3 \mathrm{~L} / \mathrm{min}$ ). Bland-Altman plot for log-transformed variables shows that the breath-signal of metabolites is independent of the exhalation flow rate. The mean of $\log _{10}$ (ratio) was found to be -0.09 . As expected, only $\sim 4 \%$ of low-intensity ions lie outside the mean $\pm 1.96 \times \mathrm{SD}$ bands. We therefore conclude that the range of flow rates between 9 and $12 \mathrm{~L} / \mathrm{min}$ are suitable for breath metabolomics using our particular configuration.

\section{Antibacterial/antiviral spirometry filter}

Patient and operator safety and hygiene are crucial factors to take into account in the clinics. For this reason, the interface between the patient and the breath analysis platform is through a disposable barrier filter, as the ones routinely used for pulmonary function testing. This is a new element incorporated in this device to allow for measuring patients with suspected respiratory infectious diseases. Until now, our system featured a mouthpiece filter used for alcohol breath tests, which would not be suitable to investigate contagious respiratory diseases. In a separate set of experiments, we examined whether these aerosol filters may have an impact on the detected metabolites. To do so, we compared the breath-signal of the same subject exhaling through the filter and subsequently exhaling without the filter. Figure $4 \mathrm{~b}$ shows the resulting comparison, represented as a Bland-Altman plot for log-transformed variables. There appears to be a small bias towards lower intensities by the use of the filter, as the mean of $\log _{10}$ (ratio) was found to be -0.17 . Moreover, only $4.6 \%$ of the signals fell outside the mean $\pm 1.96 \times$ SD boundaries. Globally, these results are consistent with previous studies suggesting that SESI-MS breath spectra using and removing aerosol filters look alike [64]. We therefore conclude that, while the antibacterial/ antiviral filters incorporated in our system may partially suppress some signal intensities, they represent a good compromise to protect the system and the operator from pathogens and to preserve the quality of the mass spectral readout of exhaled metabolites.

\section{Instrumental time drift}

Instrumental time drifts and batch effects are a common problem in untargeted metabolomics $[65,66]$. This can be especially critical in clinical studies as patient recruitment typically runs over several months/years. In order to assess whether our system showed any significant batch effect due to the date of measurement, we visualized our data using principal components analysis (PCA). Figure 5 shows the resulting plot for the first two components, whereby the labels on the left-hand side correspond to a total of 17 measuring days spanning across 1 month. No clustering according to measuring day is evident, 
Effect of exhalation flow rate on breath-signal of metabolites

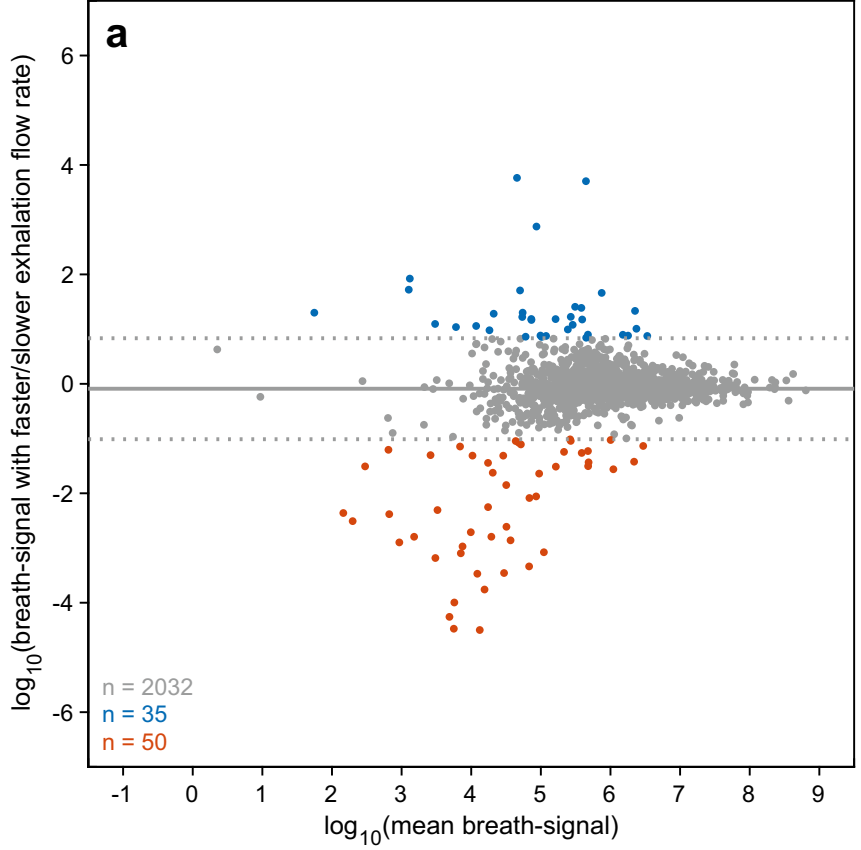

Fig. 4. Evaluation of breath mass spectra at varying exhalation flow rates and using spirometry filters. a Breath-signals of exhaled metabolites are independent of exhalation flow rate. As seen by the comparison of signals from two experiments with slower $(9.8 \pm 0.1 \mathrm{~L} / \mathrm{min})$ and faster $(12.0 \pm$ $0.3 \mathrm{~L} / \mathrm{min}$ ) exhalation flow rates. b Use of filters does not significantly

suggesting that the variance explained by these two components $(48.6 \%$ in total) cannot be attributed to a batch effect. Note that no special cleaning procedures, apart from flushing the ion source with hot nitrogen overnight, were performed

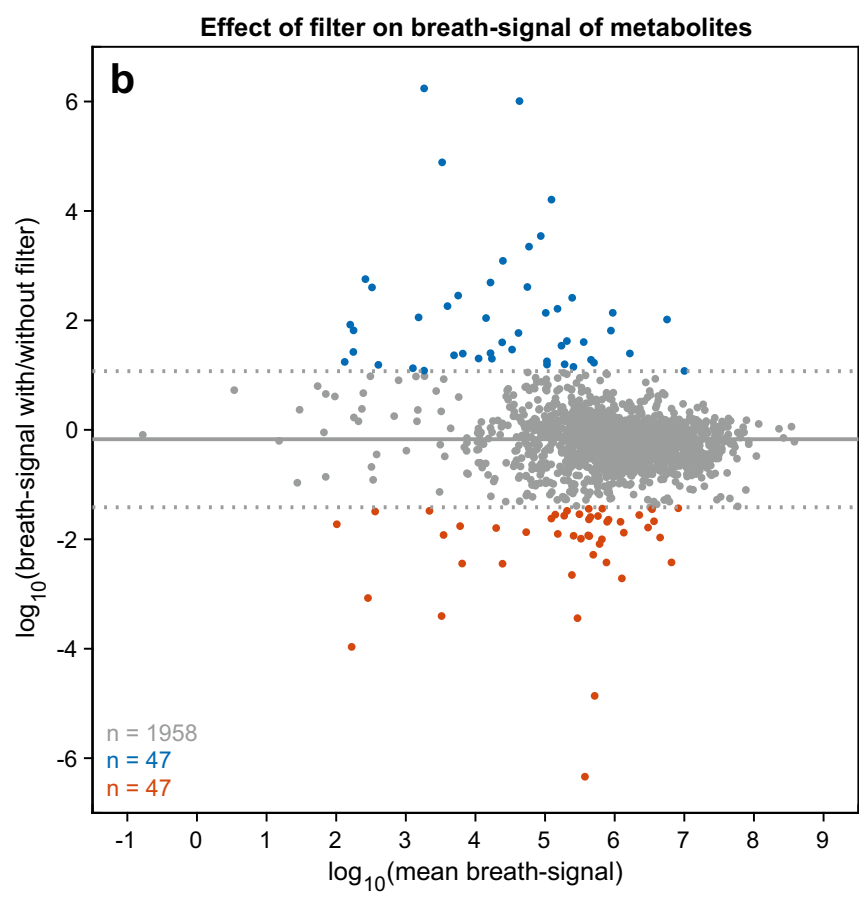

affect the breath-signals of exhaled metabolites. As seen by the comparison of signals from two experiments with and without the presence of an antibacterial/antiviral filter. In both panels, solid gray horizontal line represents the mean and dotted gray horizontal lines represent mean $\pm 1.96 \times$ SD.

during this month of operation. In contrast, on the right-hand side of Fig. 5, the same score plot is shown whereby the labels now indicate the subject number. Grouping based on the subject number is much more evident. For example, subjects 1

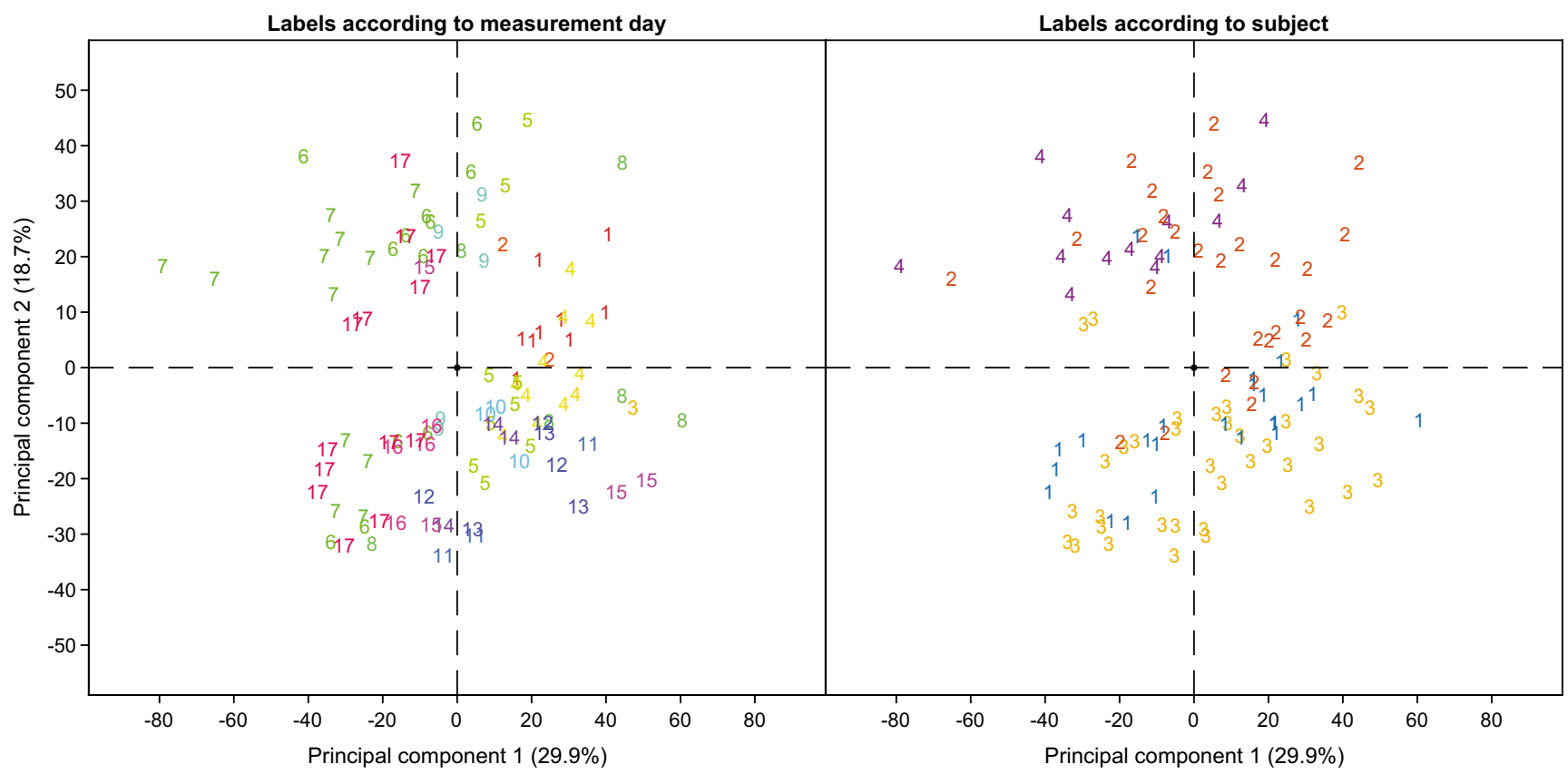

Fig. 5 Variability of SESI-HRMS breath mass spectra are dominated by inter-individual differences, rather than by batch effect. PCA score plot of all measurements with labels according to measuring day (left) and subject number (right). Grouping according to subject number is more evident than by measurement date. 
and 3 cluster together suggesting a significantly different exhaled metabolic phenotype than subjects 2 and 4 . This is also consistent with previous studies suggesting the existence of stable individual-specific metabolic traits [67-69]. The same picture emerged when we considered the 27 representative aldehydes (ESM Fig. S12). In order to provide a more objective assessment of whether significant differences exist across subjects for these metabolites, we conducted an ANOVA test followed by post hoc multiple comparison using a Bonferroni method (Table 2).

This univariate approach revealed significant differences in the breath-signal of exhaled aldehydes. Overall, the median (IQR) relative difference between individuals (considering only those $p \leq 0.05$ ) was $48.2 \%$ (39.3\%). This is consistent with inter-subject variability in blood concentrations for these particular compounds. For example, Mak et al. [70] reported CVs for 4-hydroxy-nonenal from eight healthy individuals of $95.8 \%$. In our case, mean differences between subject 1 and 2 were of $42.4 \%$ for this particular compound. It is therefore evident that the inter-subject biological variability is greater than intra-subject variability, and is consistent with the variability expected in blood levels.

\section{Fatty aldehydes as surrogate markers of oxidative stress}

Fatty aldehydes were chosen as metabolite models for this study as they are related to lipid peroxidation and oxidative stress. Oxidative stress is the trigger for the production of fatty aldehydes, such as 4-hydroxy-2-nonenal, in human metabolism [71]. Abnormally elevated values (factor two to three as compared to controls) of some of the aldehydes studied here have been associated with pathologies such as congestive heart failure [70]. Strong associations between series of metabolites, i.e., in terms of correlations, might be an indication for a common metabolic pathway, as already shown previously for series of omega-oxidation end-products of aliphatic fatty acids $[52,72]$ and aminoacids [73]. In an attempt to visualize whether an interplay between the different series of fatty aldehydes may be captured by breath analysis, we computed correlation coefficients across all measurements. A first indication suggesting that these metabolites are indeed metabolically connected is given by the fact that all of them showed positive correlations (ESM Figs. S13-15). Thus, all measured subjects had consistent (high or low) breath-signals for all 27 metabolites. One could argue that this might be an artifact as a

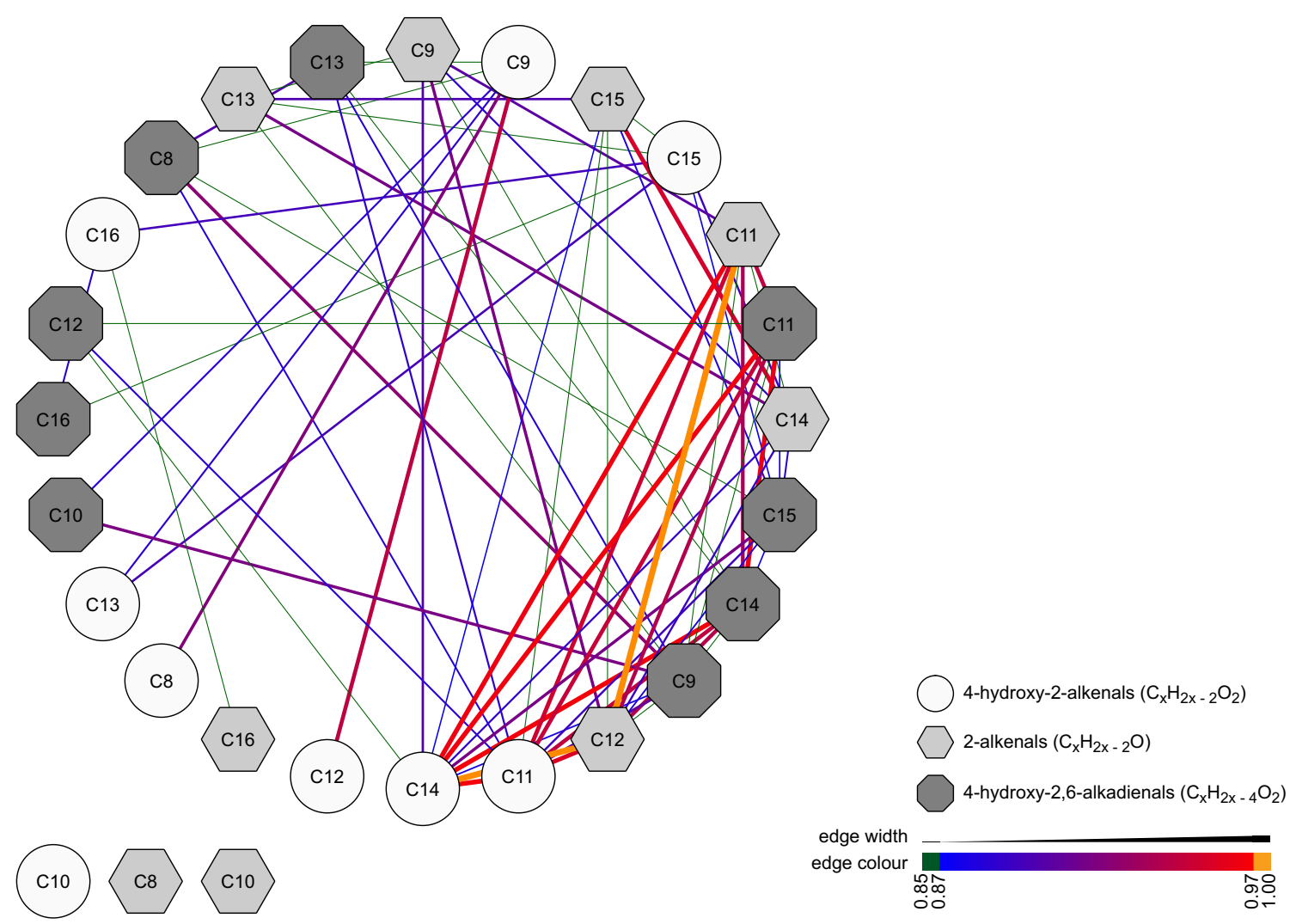

Fig. 6. Positive correlation among aldehydes suggests a common origin of mechanism of generation. Correlation network (considering Spearman's $r \geq 0.85$ ) with an average node degree of $4 \pm 2$. Note that 4 hydroxy-2-decenal, 2-octenal and 2-decenal do not pass the correlation cutoff and hence are shown at the bottom-left side. Node shape and color are based on the classes of aldehydes, whereas edge width and color depends on the correlation coefficient, as shown in the legend at the bottom-right side. 
result of different performance of the system during the different days (i.e., consistently high- or low-intensity mass spectra). However, this can be ruled out as we found that these aldehydes consistently correlated with each other, but not with the rest of the over 2,000 features considered in the breath mass spectra (ESM Fig. S16). Only around $2 \%$ of the pairwise correlations for all features correlated with $r \geq 0.85$ with the aldehydes. We therefore conclude that the observed associations for these families of compounds should encode a biological meaning. Figure 6 shows the resulting correlation network for the aldehydes. Most of the aldehydes are indeed linked with a mean \pm SD degree of $4 \pm 2(r \geq 0.85)$. This is to be expected from the metabolic point of view, as aliphatic aldehydes in humans are largely produced by a cascade of catabolic metabolism of several lipids [71]. In particular, peroxidative cleavage of polyunsaturated fatty acids by reactive oxygen species is the mechanism behind a complete series of aldehydes as those studied, including short- and mediumchain aldehydes, or hydroxy-alkenals.

\section{Conclusions}

Summing up, we presented here a series of instrumental developments aiming to standardize sampling and analysis of expired metabolites by real-time SESI-HRMS. This analytical platform was tested using a constant infusion of $\beta$-pinene vapors in the ppb range resulting in a technical variability within $3 \%$. We then tested the system during a series of repeated breath measurements from four healthy individuals. Real-time display of $\mathrm{CO}_{2}$, exhalation flow rate, and exhaled volume to the subjects during the exhalation maneuver enabled a variability for these variables within 5\%. We found no evidence that the exhalation maneuvers would induce hyperventilation, nor that the exhalation flow rates and mouthpiece filter used would have any significant impact on the quality of the metabolic breath print. We also did not find any evidence of obvious batch effect. However, despite these indications of exhalation maneuver control and reproducibility, we observed a systematic decay in the signal intensity of the shorter aldehydes across all measurements for all subjects. This compound-specific and individualindependent pattern has been rationalized as a result of the different locations of the respiratory system where the aldehydes may exchange. We hypothesize that shorter aldehydes exchange within the airways (with the bronchial blood), and longer ones primarily in the alveoli (with the pulmonary blood). Although the first exhalation may correlate better with systemic aldehyde concentrations, we recommend the collection of at least six replicate exhalations per subject and exclude the first three from the analysis. Caution should be taken when interpreting results from such measurements, especially for shorter species. Taking into account these measures, we found intra-subject variabilities is in general much lower than inter- subject variability for the aldehydes studied (6.7\% vs $48.2 \%)$. Such inter-subject differences are consistent with reported variability of such aldehydes in blood. Moreover, we found that all 27 aldehydes strongly positively correlated with each other, which is to be expected due to their common metabolic origin in humans. Overall, we conclude that this breath analysis platform and procedures described herein meet the required standards to conduct breath metabolomics studies in multi-center clinical studies. Further work to interrogate exhaled breath using this analytical platform in two different clinical settings is ongoing.

Acknowledgements This work is part of the Zurich Exhalomics project under the umbrella of University Medicine Zurich/Hochschulmedizin Zürich. Amelia Imolesi and Maya Weber are gratefully acknowledged for their administrative and experimental support.

Funding This study was funded by the Fondation Botnar, Switzerland (Professorship of Pablo Sinues), and the Swiss National Science Foundation (grants number 320030_173168 and PCEGP3_181300). J. Usemann was supported by research fellowship of the University Children's Hospital Basel.

Data availability The raw mass spectra and Exhalion files of the realtime breath measurements are available from the MetaboLights (https:// www.ebi.ac.uk/metabolights) repository (accession number MTBLS842).

\section{Compliance with ethical standards}

This study was approved by the Ethics Committee for Northwest/Central Switzerland (Determination of Optimal Procedures for Analysis of Expired Breath by Secondary Electrospray Ionization-Mass Spectrometry; 2018-01324). All participants signed an informed consent form.

Conflict of interest G. Jaumà, P. Barreiro, M. Macia Santiago and G. Vidal de Miguel have a financial interest in Exhalion and Super SESI, as these devices are commercialized by Fossil Ion Technology S.L., Malaga, Spain. K.D. Singh, G. Tancev, F. Decrue, J. Usemann, R. Appenzeller, U. Frey, and P. Sinues declare no conflict of interest.

Open Access This article is distributed under the terms of the Creative Commons Attribution 4.0 International License (http:// creativecommons.org/licenses/by/4.0/), which permits unrestricted use, distribution, and reproduction in any medium, provided you give appropriate credit to the original author(s) and the source, provide a link to the Creative Commons license, and indicate if changes were made.

\section{References}

1. Jannetto PJ, Fitzerald RL. Effective use of mass spectrometry in the clinical laboratory. Clin Chem. 2016;62(1):92-8. https://doi.org/10. 1373/clinchem.2015.248146.

2. Singh KD, Del Miguel GV, Gaugg MT, Ibanez AJ, Zenobi R, Kohler M, et al. Translating secondary electrospray ionizationhigh-resolution mass spectrometry to the clinical environment. J Breath Res. 2018;12(2):027113. https://doi.org/10.1088/17527163/aa9ee3. 
3. Risby TH, Solga SF. Current status of clinical breath analysis. Appl Phys B: Lasers Opt. 2006;85(2):421-6. https://doi.org/10.1007/ s00340-006-2280-4.

4. Teranishi R, Mon TR, Robinson AB, Gary P, Pauling L. Gas chromatography of volatiles from breath and urine. Anal Chem. 1972;44(1):18-20.

5. Pauling L, Robinson AB, Teranishi R, Cary P. Quantitative analysis of urine vapor and breath by gas-liquid partition chromatography. Proc Natl Acad Sci U S A. 1971;68:2374-6. https://doi.org/10. 1073/pnas.68.10.2374.

6. Phillips M, Cataneo RN, Chaturvedi A, Kaplan PD, Libardoni M, Mundada M, et al. Detection of an extended human volatome with comprehensive two-dimensional gas chromatography time-offlight mass spectrometry. PLoS One. 2013;8:e75274. https://doi. org/10.1371/journal.pone.0075274.

7. Fang M, Ivanisevic J, Benton HP, Johnson CH, Patti GJ, Hoang LT, et al. Thermal degradation of small molecules: a global metabolomic investigation. Anal Chem. 2015;87(21):10935-41. https://doi.org/10.1021/acs.analchem.5b03003.

8. Blake R, Monks P, Ellis A. Proton-transfer reaction mass spectrometry. Chem Rev. 2009;109:861-96.

9. Spanel P, Smith D. Progress in SIFT-MS: breath analysis and other applications. Mass Spectrom Rev. 2011;30(2):236-67. https://doi. org $/ 10.1002 /$ mas.20303

10. Li H, Zhu J, Hill JE (2018) Secondary electrospray ionization mass spectrometry for breath studies. encyclopedia of analytical chemistry. https://doi.org/10.1002/9780470027318.a9607

11. de la Mora JF. Ionization of vapor molecules by an electrospray cloud. Int J Mass Spectrom. 2011;300(2-3):182-93. https://doi. org/10.1016/j.jims.2010.09.009.

12. Li X, Huang D, Zeng J, Chan CK, Zhou Z. Positive matrix factorization: a data preprocessing strategy for direct mass spectrometrybased breath analysis. Talanta. 2019;192:32-9. https://doi.org/10. 1016/j.talanta.2018.09.020.

13. Li X, Huang DD, Du R, Zhang ZJ, Chan CK, Huang ZX, et al. Real-time breath analysis by using secondary nanoelectrospray ionization coupled to high resolution mass spectrometry. J Vis Exp. 2018;2018(133). https://doi.org/10.3791/56465.

14. Li X, Huang L, Zhu H, Zhou Z. Direct human breath analysis by secondary nano-electrospray ionization ultrahigh-resolution mass spectrometry: importance of high mass resolution and mass accuracy. Rapid Commun Mass Spectrom. 2017;31(3):301-8. https:// doi.org/10.1002/rcm.7794.

15. Huang L, Li X, Xu M, Huang Z, Zhou Z. Identification of relatively high molecular weight compounds in human breath using secondary nano electrospray ionization ultrahigh resolution mass spectrometry. Gaodeng Xuexiao Huaxue Xuebao/Chemical Journal of Chinese Universities. 2017;38(5):752-7. https://doi.org/10.7503/ cjcu20160821.

16. Zhu J, Bean HD, Wargo M, Leclair L, Hill JE. Detecting bacterial lung infections: in vivo evaluation of in vitro volatile fingerprints. J Breath Res. 2013;7(1):016003. https://doi.org/10.1088/1752-7155/ 7/1/016003.

17. Zhu JJ, Bean HD, Jimenez-Diaz J, Hill JE. Secondary electrospray ionization-mass spectrometry (SESI-MS) breathprinting of multiple bacterial lung pathogens, a mouse model study. J Appl Physiol. 2013;114(11):1544-9. https://doi.org/10.1152/japplphysiol.00099. 2013.

18. Zhu JJ, Jimenez-Diaz J, Bean HD, Daphtary NA, Aliyeva MI, Lundblad LKA, et al. Robust detection of P. aeruginosa and S. aureus acute lung infections by secondary electrospray ionizationmass spectrometry (SESI-MS) breathprinting: from initial infection to clearance. J Breath Res. 2013;7(3):037106. Artn 037106. https:// doi.org/10.1088/1752-7155/7/3/037106.
19. Bean HD, Zhu J, Hill JE. Characterizing bacterial volatiles using secondary electrospray ionization mass spectrometry (SESI-MS). J Vis Exp. 2011;(52):e2664. https://doi.org/10.3791/2664.

20. Zhu J, Bean HD, Kuo Y-M, Hill JE. Fast detection of volatile organic compounds from bacterial cultures by secondary electrospray ionization-mass spectrometry. J Clin Microbiol. 2010;48(12):4426-31. https://doi.org/10.1128/JCM.00392-10.

21. Li H, Zhu J. Differentiating antibiotic-resistant staphylococcus aureus using secondary electrospray ionization tandem mass spectrometry. Anal Chem. 2018;90(20):12108-15. https://doi.org/10. 1021/acs.analchem.8b03029.

22. Zamora D, Amo-Gonzalez M, Lanza M, Fernandez de la Mora G, Fernandez de la Mora J. Reaching a vapor sensitivity of 0.01 parts per quadrillion in the screening of large volume freight. Anal Chem. 2018. https://doi.org/10.1021/acs.analchem.7b00795.

23. Aernecke MJ, Mendum T, Geurtsen G, Ostrinskaya A, Kunz RR. Vapor pressure of hexamethylene triperoxide diamine (HMTD) estimated using secondary electrospray ionization mass spectrometry. J Phys Chem A. 2015;119(47):11514-22. https://doi.org/10.1021/ acs.jpca.5b08929.

24. Dillon LA, Stone VN, Croasdell LA, Fielden PR, Goddard NJ, Paul Thomas CL. Optimisation of secondary electrospray ionisation (SESI) for the trace determination of gas-phase volatile organic compounds. Analyst. 2010;135(2):306-14. https://doi.org/10. 1039/b918899a

25. Ong TH, Mendum T, Geurtsen G, Kelley J, Ostrinskaya A, Kunz R. Use of mass spectrometric vapor analysis to improve canine explosive detection efficiency. Anal Chem. 2017;89(12):6482-90. https://doi.org/10.1021/acs.analchem.7b00451.

26. Li H, Xu M, Zhu J. Headspace gas monitoring of gut microbiota using targeted and globally optimized targeted secondary electrospray ionization mass spectrometry. Anal Chem. 2019;91(1):854-63. https://doi.org/10.1021/acs.analchem. $8 \mathrm{~b} 03517$.

27. Cristescu SM, Kiss R, te Lintel Hekkert S, Dalby M, Harren FJM, Risby TH, et al. Real-time monitoring of endogenous lipid peroxidation by exhaled ethylene in patients undergoing cardiac surgery. Am J Physiol - Lung Cell Mol Physiol. 2014;307(7):L509-15. https://doi.org/10.1152/ajplung.00168.2014.

28. Bikov A, Paschalaki K, Logan-Sinclair R, Horváth I, Kharitonov $\mathrm{SA}$, Barnes PJ, et al. Standardised exhaled breath collection for the measurement of exhaled volatile organic compounds by proton transfer reaction mass spectrometry. BMC Pulm Med. 2013;13(1): 43. https://doi.org/10.1186/1471-2466-13-43.

29. Boshier PR, Marczin N, Hanna GB. Repeatability of the measurement of exhaled volatile metabolites using selected ion flow tube mass spectrometry. J Am Soc Mass Spectrom. 2010;21(6):1070-4. https://doi.org/10.1016/j.jasms.2010.02.008.

30. Marczin N, Kharitonov SA, Yacoub MH, Barnes PJ (2002) Disease markers in exhaled breath. Disease Markers in Exhaled Breath. New York: CRC Press.

31. Sukul P, Schubert JK, Kamysek S, Trefz P, Miekisch W. Applied upper-airway resistance instantly affects breath components: a unique insight into pulmonary medicine. J Breath Res. 2017;11(4):ARTN 047108. https://doi.org/10.1088/1752-7163/ aa8d86.

32. Sukul P, Schubert JK, Oertel P, Kamysek S, Taunk K, Trefz P, et al. FEV manoeuvre induced changes in breath VOC compositions: an unconventional view on lung function tests. Sci Rep. 2016;6:ARTN 28029. https://doi.org/10.1038/srep28029.

33. Pritam S, Phillip T, Jochen KS, Wolfram M. Immediate effects of breath holding maneuvers onto composition of exhaled breath. J Breath Res. 2014;8(3):037102.

34. Brett RW, Joachim DP, Michelle MA, Matthew AS, Terence HR, Michael CM. Standardization of the collection of exhaled breath 
condensate and exhaled breath aerosol using a feedback regulated sampling device. J Breath Res. 2017;11(4):047107.

35. Keller BO, Sui J, Young AB, Whittal RM. Interferences and contaminants encountered in modern mass spectrometry. Anal Chim Acta. 2008;627(1):71-81. https://doi.org/10.1016/j.aca.2008.04.043.

36. Schlosser A, Volkmer-Engert R. Volatile polydimethylcyclosiloxanes in the ambient laboratory air identified as source of extreme background signals in nanoelectrospray mass spectrometry. J Mass Spectrom. 2003;38(5):523-5. https:// doi.org/10.1002/jms.465.

37. Bland JM, Altman DG. Statistics notes .21. Measurement error (vol 312, pg 1654, 1996). Br Med J. 1996;313(7059):744-744.

38. Kessner D, Chambers M, Burke R, Agus D, Mallick P. ProteoWizard: open source software for rapid proteomics tools development. Bioinformatics. 2008;24(21):2534-6. https://doi. org/10.1093/bioinformatics/btn323.

39. Wong JWH, Durante C, Cartwright HM. Application of fast Fourier transform cross-correlation for the alignment of large chromatographic and spectral datasets. Anal Chem. 2005;77(17):5655-61. https://doi.org/10.1021/ac050619p.

40. Kind T, Fiehn O. Seven Golden Rules for heuristic filtering of molecular formulas obtained by accurate mass spectrometry. BMC Bioinf. 2007;8:105. Artn 105. https://doi.org/10.1186/14712105-8-105.

41. Birken T, Schubert J, Miekisch W, Nöldge-Schomburg G. A novel visually $\mathrm{CO} 2$ controlled alveolar breath sampling technique. Technol Health Care. 2006;14(6):499-506.

42. Cope KA, Watson MT, Foster WM, Sehnert SS, Risby TH. Effects of ventilation on the collection of exhaled breath in humans. J Appl Physiol. 2004;96(4):1371-9. https://doi.org/10.1152/japplphysiol. 01034.2003.

43. Doran SLF, Romano A, Hanna GB. Optimisation of sampling parameters for standardised exhaled breath sampling. J Breath Res. 2018;12(1):ARTN 016007. https://doi.org/10.1088/1752-7163/ aa8a46.

44. Solga SF, Mudalel M, Spacek LA, Lewicki R, Tittel F, Loccioni C, et al. Factors influencing breath ammonia determination. J Breath Res. 2013;7(3)037101. https://doi.org/10.1088/1752-7155/7/3/ 037101.

45. Pascale C, Guillevic M, Ackermann A, Leuenberger D, Niederhauser B. Two generators to produce SI-traceable reference gas mixtures for reactive compounds at atmospheric levels. Meas Sci Technol. 2017;28(12):ARTN 124002. https://doi.org/10.1088/ 1361-6501/aa870c.

46. Barrios-Collado C, Vidal-de-Miguel G, Martinez-Lozano Sinues P. Numerical modeling and experimental validation of a universal secondary electrospray ionization source for mass spectrometric gas analysis in real-time. Sensors Actuators B: Chem. 2016;223: 217-25. https://doi.org/10.1016/j.snb.2015.09.073.

47. García-Gómez D, Bregy L, Barrios-Collado C, Vidal-de-Miguel G, Zenobi R. Real-time high-resolution tandem mass spectrometry identifies furan derivatives in exhaled breath. Anal Chem. 2015;87(13):6919-24. https://doi.org/10.1021/acs.analchem. $5 \mathrm{~b} 01509$.

48. García-Gómez D, Martínez-Lozano Sinues P, Barrios-Collado C, Vidal-De-Miguel G, Gaugg M, Zenobi R. Identification of 2alkenals, 4-hydroxy-2-alkenals, and 4-hydroxy-2,6-alkadienals in exhaled breath condensate by UHPLC-HRMS and in breath by real-time HRMS. Anal Chem. 2015;87(5):3087-93. https://doi. org/10.1021/ac504796p.

49. Garcia-Gomez D, Gaisl T, Bregy L, Martinez-Lozano Sinues P, Kohler M, Zenobi R. Secondary electrospray ionization coupled to high-resolution mass spectrometry reveals tryptophan pathway metabolites in exhaled human breath. Chem Commun. 2016;52(55):8526-8. https://doi.org/10.1039/C6CC03070J.
50. Garcia-Gomez D, Gaisl T, Bregy L, Cremonesi A, Sinues PML, Kohler M, et al. Real-time quantification of amino acids in the exhalome by secondary electrospray ionization-mass spectrometry: a proof-of-principle study. Clin Chem. 2016;62(9):1230-7. https:// doi.org/10.1373/clinchem.2016.256909.

51. Gaugg MT, Engler A, Nussbaumer-Ochsner Y, Bregy L, Stoberl AS, Gaisl T, et al. Metabolic effects of inhaled salbutamol determined by exhaled breath analysis. J Breath Res. 2017;11(4): 046004. ARTN 046004. https://doi.org/10.1088/1752-7163/ aa7caa.

52. Gaugg MT, Bruderer T, Nowak N, Eiffert L, Sinues PML, Kohler $\mathrm{M}$, et al. Mass-spectrometric detection of omega-oxidation products of aliphatic fatty acids in exhaled breath. Anal Chem. 2017;89(19): 10329-34. https://doi.org/10.1021/acs.analchem.7b02092.

53. Tejero Rioseras A, Singh KD, Nowak N, Gaugg MT, Bruderer T, Zenobi R, et al. Real-time monitoring of tricarboxylic acid metabolites in exhaled breath. Anal Chem. 2018;90(11):6453-60. https:// doi.org/10.1021/acs.analchem.7b04600.

54. Alary J, Guéraud F, Cravedi JP. Fate of 4-hydroxynonenal in vivo: disposition and metabolic pathways. Mol Aspects Med. 2003;24(45):177-87. https://doi.org/10.1016/S0098-2997(03)00012-8.

55. Esterbauer H, Schaur RJ, Zollner H. Chemistry and biochemistry of 4-hydroxynonenal, malonaldehyde and related aldehydes. Free Radical Biol Med. 1991;11(1):81-128. https://doi.org/10.1016/ 0891-5849(91)90192-6.

56. Flor AC, Kron SJ. Lipid-derived reactive aldehydes link oxidative stress to cell senescence. Cell Death Dis. 2016;7:ARTN e2366. https://doi.org/10.1038/cddis.2016.275.

57. Rahman I, Biswas SK. Non-invasive biomarkers of oxidative stress: reproducibility and methodological issues. Redox Report. 2004;9(3):125-43. https://doi.org/10.1179/135100004225005219.

58. Schneider C, Porter NA, Brash AR. Routes to 4-hydroxynonenal: fundamental issues in the mechanisms of lipid peroxidation. J Biol Chem. 2008;283(23):15539-43. https://doi.org/10.1074/jbc. R800001200.

59. Spickett CM. The lipid peroxidation product 4-hydroxy-2-nonenal: advances in chemistry and analysis. Redox Biol. 2013;1(1):145-52. https://doi.org/10.1016/j.redox.2013.01.007.

60. Anderson JC, Hlastala MP. Breath tests and airway gas exchange. Pulm Pharmacol Ther. 2007;20(2):112-7. https://doi.org/10.1016/j. pupt.2005.12.002.

61. Anderson JC, Babb AL, Hlastala MP. Modeling soluble gas exchange in the airways and alveoli. Ann Biomed Eng. 2003;31(11):1402-22. https://doi.org/10.1114/1.1630600.

62. Hlastala MP, Powell FL, Anderson JC. Airway exchange of highly soluble gases. J Appl Physiol. 2013;114(5):675-80. https://doi.org/ 10.1152/japplphysiol.01291.2012.

63. Kramer C, Mochalski P, Unterkofler K, Agapiou A, Ruzsanyi V, Liedl KR. Prediction of blood:air and fat:air partition coefficients of volatile organic compounds for the interpretation of data in breath gas analysis. J Breath Res. 2016;10(1):Artn 017103. https://doi.org/ 10.1088/1752-7155/10/1/017103.

64. Martínez-Lozano P, Fernández de la Mora J. Electrospray ionization of volatiles in breath. Int J Mass spectrom. 2007;265(1):68-72. https://doi.org/10.1016/j.ijms.2007.05.008.

65. Rusilowicz M, Dickinson M, Charlton A, O'Keefe S, Wilson J. A batch correction method for liquid chromatography-mass spectrometry data that does not depend on quality control samples. Metabolomics. 2016;12:56. https://doi.org/10.1007/s11306-0160972-2.

66. Salerno S, Mehrmohamadi M, Liberti MV, Wan MT, Wells MT, Booth JG, et al. RRmix: a method for simultaneous batch effect correction and analysis of metabolomics data in the absence of internal standards. PLoS One. 2017;12(6):ARTN e0179530. https://doi.org/10.1371/journal.pone.0179530. 
67. Assfalg M, Bertini I, Colangiuli D, Luchinat C, Schäfer H, Schütz B, et al. Evidence of different metabolic phenotypes in humans. Proc Natl Acad Sci USA. 2008;105(5):1420-4.

68. Bernini P, Bertini I, Luchinat C, Nepi S, Saccenti E, Schäfer H, et al. Individual human phenotypes in metabolic space and time. J Proteome Res. 2009;8(9):4264-71. https://doi.org/10.1021/ pr900344m.

69. Sinues PML, Kohler M, Zenobi R. Human breath analysis may support the existence of individual metabolic phenotypes. PLoS One. 2013;8(4):ARTN e59909. https://doi.org/10.1371/journal. pone.0059909.

70. Mak S, Lehotay DC, Yazdanpanah M, Azevedo ER, Liu PP, Newton GE. Unsaturated aldehydes including 4-OH-nonenal are elevated in patients with congestive heart failure. J Card Fail. 2000;6(2):108-14. https://doi.org/10.1054/jcaf.2000.7272.
71. Rizzo WB. Fatty aldehyde and fatty alcohol metabolism: Review and importance for epidermal structure and function. Bba-Mol Cell Biol L. 2014;1841(3):377-89. https://doi.org/10.1016/j.bbalip. 2013.09.001.

72. Gaugg MT, Nussbaumer-Ochsner Y, Bregy L, Engler A, Stebler N, Gaisl T, et al. Real-time breath analysis reveals specific metabolic signatures of COPD exacerbations. Chest. 2019. https://doi.org/10. 1016/j.chest.2018.12.023.

73. Gaugg MT, Engler A, Bregy L, Nussbaumer-Ochsner Y, Eiffert L, Bruderer T, et al. Molecular breath analysis supports altered amino acid metabolism in idiopathic pulmonary fibrosis. Respirology. 2019. https://doi.org/10.1111/resp.13465.

Publisher's note Springer Nature remains neutral with regard to jurisdictional claims in published maps and institutional affiliations. 